\title{
Relaxant effect of quercetin on rabbit isolated bladder smooth muscles contractions
}

\author{
Hassan Sadraei* ${ }^{\mathbb{D}}$, Sabihe Tabesh ${ }^{\mathbb{D}}$ \\ Department of Pharmacology and Toxicology, School of Pharmacy and Pharmaceutical Sciences, Isfahan University of Medical Sciences, Isfahan, I.R. \\ Iran
}

\section{A R T I C L E I N F O}

Article Type:

Original Article

\section{Article History:}

Received: 14 February 2020

Accepted: 5 May 2020

\section{Keywords:}

Quercetin

Bladder

Acetylcholine

Flavonoids

Electrical field stimulation

\begin{abstract}
A B S T R A C T
Introduction: Quercetin is a flavonoid compound found in many medicinal plants. Antispasmodic effect of quercetin has been reported in ileum and uterus smooth muscles but not in bladder. Therefore, the objective of this research was to investigate relaxant effect of quercetin in rabbit isolated bladder.

Methods: Male rabbit was asphyxiated with carbon dioxide and then sacrificed. The whole bladder was dissected out and placed in oxygenated Tyrode's solution. Isolated bladder was cut into longitudinal strips and placed in an organ bath for contraction studies. Contractions were induced with $\mathrm{KCl}(20 \mathrm{mM})$, acetylcholine $(5 \mu \mathrm{M})$ and electrical field stimulation (EFS). Full inhibitory concentration-response curve was constructed for quercetin following addition of above spasmogens. Quercetin was added into the organ bath with 2 fold increments in concentration until maximum response was achieved. Nifedipine was used as positive control group and equivalent volume of quercetin vehicle (water + DMSO) was used as negative control group.

Results: Quercetin ( $4 \mu \mathrm{g} / \mathrm{mL}$ to $640 \mu \mathrm{g} / \mathrm{mL})$ in a concentration dependent manner inhibited isolated bladder strips contracted by $\mathrm{KCl}\left(\mathrm{IC}_{50}=159 \pm 25 \mu \mathrm{g} / \mathrm{mL}\right)$, acetylcholine $\left(\mathrm{IC}_{50}=43 \pm 9.1 \mu \mathrm{g} /\right.$ $\mathrm{mL})$ and $\mathrm{EFS}\left(\mathrm{IC}_{50}=38 \pm 9.3 \mu \mathrm{g} / \mathrm{mL}\right)$. In the highest used concentration, quercetin completely removed contractile responses to $\mathrm{KCl}$, acetylcholine and electrical filed stimulation (EFS). Nifedipine totally inhibited $\mathrm{KCl}$ response $\left(\mathrm{IC}_{50}=115 \pm 36 \mathrm{ng} / \mathrm{mL}\right)$ but only partially inhibited acetylcholine and EFS responses.

Conclusion: These results confirm the relaxant effect of quercetin on rabbit bladder and if similar effects are seen in human studies, then quercetin would be a suitable drug candidate to be investigated for bladder incontinence.
\end{abstract}

Implication for health policy/practice/research/medical education:

This paper provides pharmacological evidence for spasmolytic action of quercetin on isolated bladder and therefore it might be useful for treatment of bladder incontinence.

Please cite this paper as: Sadraei H, Tabesh S. Relaxant effect of quercetin on rabbit isolated bladder smooth muscles contractions. J Herbmed Pharmacol. 2021;10(1):61-67. doi: 10.34172/jhp.2021.05.

\section{Introduction}

Urinary bladder function is appropriate collection and excretion of urine. Collection of urine is performed under relatively low bladder wall pressure. In other words, urine collection is possible when bladder smooth muscles are relaxed (1). Dysfunction in bladder smooth muscles activities may result in bladder incontinence. Overactive bladder syndrome due to involuntary contraction of bladder smooth muscle in the collection phase is a common problem that has received less attention. Urinary incontinence is enhanced with age and is considered as a serious problem in elderly (1). Detrusor accounts for most of smooth muscle contractions in the bladder sac. Relaxant capability of detrusor smooth muscle during collection periods and its contraction during micturition has important role in normal bladder activities (1). Tricyclic antidepressants and antimuscarinic drugs such as propantheline reduce bladder contractions and increase bladder capacity. Oxybutynin also has a direct relaxant effect on urinary smooth muscle. However, 
consumption of these drugs is accompanied by unwanted side effects and is not satisfactory for most patients with urinary incontinence (2). Therefore, nowadays, more attention is given to herbal medicine as an alternative treatment. Chamomile (Matricaria chamomilla L.) is one these herbal medicines recommended for bladder incontinence (3). However, both hydroalcoholic and aqueous extracts of chamomile possessed both spasmodic and antispasmodic activities on isolated bladder (3). Thus, its consumption in patients with urinary incontinence may aggravate involuntary micturition. Fractionation of hydroalcoholic extract of chamomile indicated that flavonoids rich fraction mainly had relaxant properties (4). Study of antispasmodic effect of flavonoids rich fraction on smooth muscle showed that flavonoids fraction was ten times more potent than the original hydroalcoholic extract (4). Therefore, it can be concluded that flavonoids might be responsible for antispasmodic activity. Quercetin, apigenin, luteolin, apigetrin, apiin, rutin and quercimeritrin are some of flavonoids constituents identified in chamomile (5). Among them quercetin is the most abundant flavonoid found in chamomile (5). In animal model and in vitro pharmacological studies several biological activities have been reported for quercetin including antioxidant, antiviral, anticancer, anti-inflammatory, immunomodulatory, lipid-peroxidase inhibition and antiplatelets activities (6). Pharmacological studies on guinea pig ileum contractions showed that quercetin was a relatively potent relaxant of ileum smooth muscles $(7,8)$. Furthermore, quercetin inhibited rat uterus contractions (9). Other studies indicated that quercetin was a relaxant of tracheal smooth muscle (10). However, so far there is no report on antispasmodic effect of quercetin on bladder contractions. Therefore, the objective of this research was to investigate and quantify relaxant effect of quercetin on rabbit isolated bladder contractions.

\section{Materials and Methods}

Drug and solutions

Tyrode's physiological solution was made up in distilled water with the following compositions $(\mathrm{NaCl} 136.9 \mathrm{mM}$; $\mathrm{KCl} 2.68 \mathrm{mM} ; \mathrm{CaCl}_{2} 1.8 \mathrm{mM} ; \mathrm{MgCl}_{2} 1.05 \mathrm{mM} ; \mathrm{NaH}_{2} \mathrm{PO}_{4}$ $0.42 \mathrm{mM}$; $\mathrm{NaHCO}_{3} 11.9 \mathrm{mM}$ and glucose $5.55 \mathrm{mM}$ ) and gassed with oxygen. Potassium chloride was prepared in distilled water as $2 \mathrm{M}$ stock solution. Quercetin was made up as $40 \mathrm{mg} / \mathrm{mL}$ stock solution in dimethylsulphoxide (DMSO), further dilution was prepared in 50\% DMSO. Acetylcholine was dissolved in distilled water as $100 \mathrm{mM}$ stock solution and acidified with $1 \%$ acetic acid. Further serial dilution was made up in distilled water. Nifedipine initially was prepared in DMSO $(20 \mathrm{mg} / \mathrm{mL}, 2 \mathrm{mg} / \mathrm{mL}$ and $200 \mu \mathrm{g} / \mathrm{mL}$ ) and further diluted with distilled water. Daily dilutions were prepared form the main stock solutions. Acetylcholine, nifedipine and quercetin were purchased from Sigma-Aldrich (St. Louis, MO). Other chemicals were from Merck (Germany).

Bladder contraction studies

Local domestic rabbits bred in open field in Isfahan were housed in School of Pharmacy and Pharmaceutical Sciences' animal house with free access to food and water at room temperature. Animal handling was approved by university ethical committee for handling laboratory animal (IR.MUI.RESEARCH.REC.1398.542). On experiment day, one male rabbit (800-1500 g) was anesthetized with carbon dioxide and then sacrificed. Abdominal wall was opened up and urinary bladder was carefully dissected out and placed in oxygenated Tyrode's solution. The tissue was transferred into pharmacology lab and cut into longitudinal strips. Both ends of the tissue were tied up with cotton thread. One end was secured into tissue hook and placed into organ bath (Palmer, England) at $37^{\circ} \mathrm{C}$ and continuously bubbled with oxygen. Other end of the thread was tied up to lever of isotonic transducer (Harvard's) connected to Harvard Oscillograph apparatus pen recorded device. The Oscillograph was calibrated according to apparatus manual. The tissue was suspended in the organ bath under $1 \mathrm{~g}$ tension and washed several times with fresh Tyrode's solution and allowed to relax into a stable baseline. First of all, the tissue was challenged with single concentration of acetylcholine $(1 \mu \mathrm{M})$. Only the tissue responded to acetylcholine was used in this research. Bladder strip contracted with addition of $\mathrm{KCl}$ and acetylcholine into organ bath as well as application of electrical filed stimulation (EFS). Final bath concentration of $\mathrm{KCl}$ and acetylcholine was $20 \mathrm{mM}$ and $5 \mu \mathrm{M}$, respectively. These concentrations caused $60 \%-80 \%$ of maximum contractile responses in the bladder strip. Electrical stimulation (EFS: $6 \mathrm{~V}, 1 \mathrm{~s}, 50 \mathrm{~Hz}$ ) was applied via a pair of platinum wires located alongside of the bladder strip. Pilot studies were made to discover best EFS parameters to give reproducible responses for long period of time. Effects of quercetin and nifedipine on $\mathrm{KCl}$ induced contraction were studied in cumulative manner. Effects of drugs on acetylcholine and EFS contractions were investigated in a non-cumulative manner. Acetylcholine was in contact with the tissue for 30 second before it was washed out. Washing was done by emptying the bath and filling it with fresh Tyrode's solution. For consistency, the washing process was performed trice. Contractions induced by acetylcholine and EFS were repeated at 5-minute interval. Effects of drugs were examined on the tissue when at least three consistent responses were obtained. Quercetin concentrations were selected after a series of pilot experiments. Full concentration response curve was obtained for quercetin using two-fold increments in the concentration. Nifedipine was added into the bath using four folds increments in concentration. As appropriate, each concentration of the drug was at least 5 or 10 minutes in contract with the tissue before its effect was evaluated. 
Each experiment was conducted in parallel with a time matched control tissues treated with equivolume amount of vehicle (DMSO).

Contraction assessment and statistical analysis Bladder smooth muscle contraction amplitude was measured from baseline position prior to addition of stimulus. Tissue responses to drugs were expressed as percentage of initial contraction for each bladder strip. Drug effects were examined on six bladder strips taken from different animal. The results were presented as mean \pm standard error of mean (SEM). Full concentration response curve was plotted for each set of experiments. Drug concentration causing 50\% inhibition of maximum response $\left(\mathrm{IC}_{50}\right)$ was calculated for each group of the results. For statistical analysis inter-group comparisons were made with one-way analysis of variance (ANOVA), and further compared with their time-matched controls using Student's $t$ test. Differences were considered statistically significant for $\mathrm{P}<0.05$. SigmaPlot computer program (version 11) was used for plotting the data and statistical analysis.

\section{Results}

Rabbit bladder strip suspended in Tyrode's solution in the organ bath gradually relaxed toward a stable baseline with substantial washing. In a series of pilot experiments effect of several concentrations of acetylcholine and $\mathrm{KCl}$ was examined on the tissue strips for determine optimum concentration. Addition of $\mathrm{KCl}(20 \mathrm{mM})$ into the organ bath solution, produced a swift contraction reaching to its peak within a minute and then remained sustained during the experiment period. Addition of equivolume amount of vehicle (DMSO + water) only at its highest using concentration (3.2\% in the final bath concentration) attenuated $\mathrm{KCl}$ response just by 19\% (Figure 1). Quercetin in a concentration dependent manner inhibited tonic contraction induced by $\mathrm{KCl}$ (Figure 1). The inhibitory concentration was observed with $20 \mu \mathrm{g} / \mathrm{mL}$ quercetin in the bath. Total inhibition was achieved with $640 \mu \mathrm{g} /$ $\mathrm{mL}$ quercetin in the bath. The inhibitory concentration causing $50 \%$ of maximum response $\left(\mathrm{IC}_{50}\right)$ was calculated as $159 \pm 25 \mu \mathrm{g} / \mathrm{mL}(\mathrm{n}=6)$.

Addition of acetylcholine $(5 \mu \mathrm{M})$ into the organ bath produced a sharp contraction in bladder strip, reaching its peak within 30 seconds contact time. After washing the tissue with fresh Tyrode's solution, the tissue tension returned to its initial baseline position. Addition of quercetin into the bath with $4 \mu \mathrm{g} / \mathrm{mL}$ concentrations and above reduced bladder responses to acetylcholine. Effect of quercetin was concentration dependent and total inhibition was seen with $320 \mu \mathrm{g} / \mathrm{mL}$ bath concentration (Figure 2). The $\mathrm{IC}_{50}$ value was calculated as $43 \pm 9.1 \mu \mathrm{g} /$ $\mathrm{mL}(\mathrm{n}=6)$. Addition of equivolume of quercetin vehicle (DMSO + water) had no significant effect on acetylcholine responses (Figure 2).

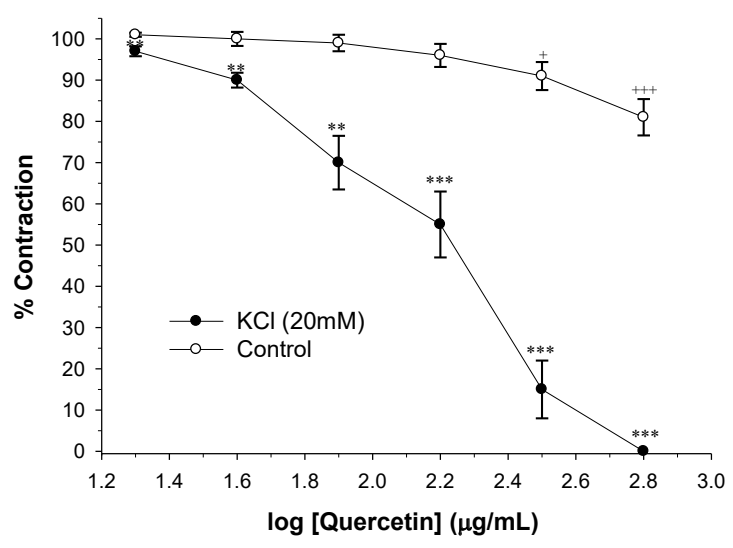

Figure 1. Inhibitory concentration-response curve of cumulative addition of quercetin on tension development in rabbit isolated bladder to $\mathrm{KCl}$. Control group represented parallel time-matched tissues treated with equivalent volume of the vehicle. Results are given as mean and vertical bars indicate standard error of mean $(n=6)$. DMSO at its highest used concentration (3.2\%), partially but significantly attenuated the $\mathrm{KCl}$ response (ANOVA, $+P<0.05,+++P<0.001$ ). Asterisk symbols indicate statistically significant difference between the test group and its corresponding vehicle treated control group $\left({ }^{* *} P<0.01,{ }^{* * *} P<0.001\right.$, Student's $t$ test).

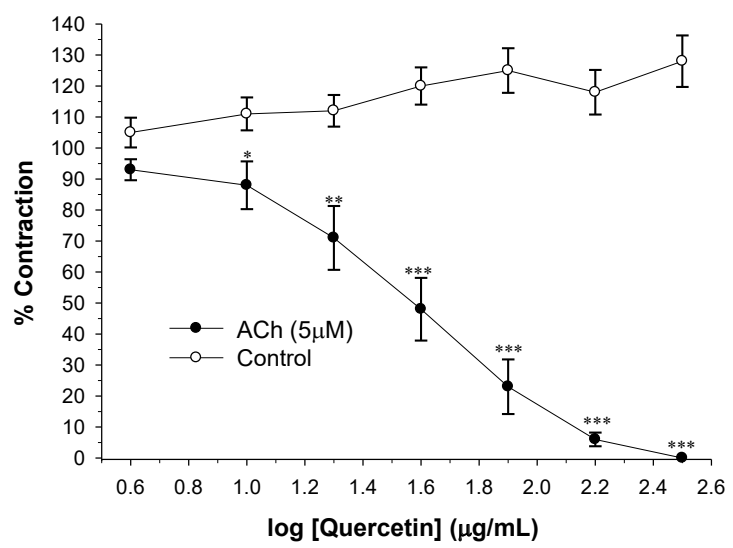

Figure 2. Inhibitory concentration-response curve of non-cumulative addition of quercetin on tension development in rabbit isolated bladder to acetylcholine (ACh). Control group represents parallel time-matched tissues treated with equivalent volume of the vehicle. Results are given as mean, and vertical bars indicate standard error of mean $(n=6)$. There was no statistically significant changes in response of time-matched controls over the course of the experiment (ANOVA). Asterisk symbols indicate statistically significant difference between the test group and its corresponding vehicle treated control group $\left({ }^{*} P<0.05,{ }^{* *} P<0.01\right.$, ${ }^{* * *} P<0.001$, Student's $t$ test).

Application of electrical field stimulation (EFS) to the bladder strip suspended in the organ bath induced a rapid contraction which quickly returned to its baseline following cessation of stimulation. As shown in Figure 3, quercetin concentration dependently caused relaxation of isolated bladder strips. The inhibition of EFS contraction was started with $8 \mu \mathrm{g} / \mathrm{mL}$ quercetin in the bath and with bath concentration of $256 \mu \mathrm{g} / \mathrm{mL}$ the EFS responses were abolished. The $\mathrm{IC}_{50}$ value for inhibition of EFS response 
was calculated as $38 \pm 9.3 \mu \mathrm{g} / \mathrm{mL}(\mathrm{n}=6)$. Addition of equivolume of quercetin vehicle (water + DMSO) into the tissue bath had no inhibitory effect of bladder strip contractions induced by EFS (Figure 3).

Nifedipine was used as a standard drug with relaxant effect on smooth muscle tissues. As expected nifedipine $(0.4 \mathrm{ng} / \mathrm{mL}$ to $6.4 \mu \mathrm{g} / \mathrm{mL})$ in a concentration dependent manner inhibited sustained tonic contractions induced by $\mathrm{KCl}$ (Figure 4). The $\mathrm{IC}_{50}$ value was calculated $115 \pm 36$ $\mathrm{ng} / \mathrm{mL}(\mathrm{n}=6)$. On the other hand, nifedipine partially attenuated bladder strips responses to acetylcholine (5mM). Maximum inhibition was 39\% and achieved with $1.6 \mu \mathrm{g} / \mathrm{mL}$ nifedipine in the bath (Figure 4). No more inhibition was seen with further increase in nifedipine concentration (Figure 4). Nifedipine at higher concentrations ( $4 \mu \mathrm{g} / \mathrm{mL}$ to $256 \mu \mathrm{g} / \mathrm{mL}$ ) partially inhibited isolated bladder strips responses to EFS (Figure 5). With maximum used concentration of nifedipine in the bath $(256 \mu \mathrm{g} / \mathrm{mL})$ still $48 \%$ of the initial response was remained (Figure 5).

\section{Discussion}

Urinary bladder is a stretchable sac and its wall mostly composed of smooth muscle layers. Appropriate relaxation and contraction of these smooth muscles are responsible for storage and regular micturition. Disordered micturition is a common problem particularly in elderly and in patients with diseases such as diabetes mellitus $(11,12)$. Many causes of incontinence are functional and should in principle be amenable to drugs acting on urinary tract smooth muscle or on the nerve innervating them. Urinary

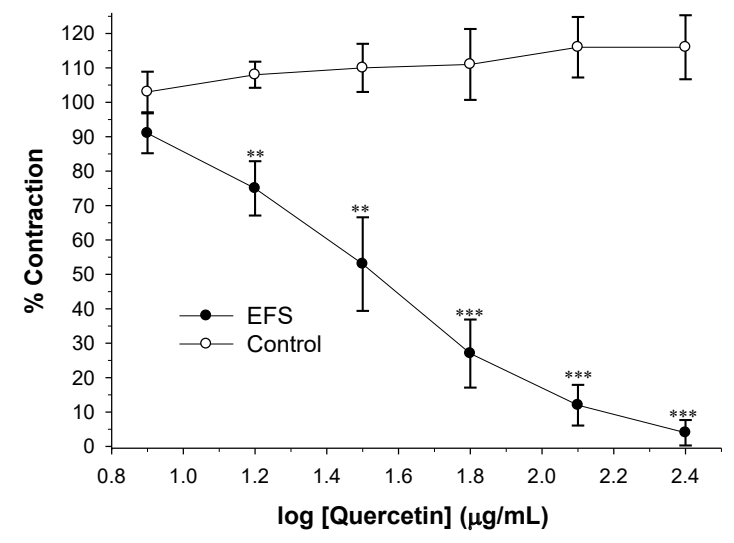

Figure 3. Inhibitory concentration-response curve of non-cumulative addition of quercetin on tension development in rabbit isolated bladder to electrical field stimulation (EFS, frequency $50 \mathrm{~Hz}$, train duration $1 \mathrm{~s}$, voltage output $6 \mathrm{~V}$ ). Control group represents parallel time-matched tissues treated with equivalent volume of the vehicle. Results are given as mean, and vertical bars indicate standard error of mean $(n=6)$. There was no statistically significant changes in response of time-matched controls over the course of the experiment (ANOVA). Asterisk symbols indicate statistically significant difference between the test group and its corresponding vehicle treated control group $\left({ }^{* *} P<0.01,{ }^{* * *} P<0.001\right.$, Student's $t$ test). bladder receives parasympathetic and sympathetic as well as non-adrenergic non-cholinergic (NANC) innervations (13). Parasympathetic sacral innervations cause detrusor muscle contraction while bladder neck and trigone receives sympathetic innervations. Incontinence caused by neurogenic detrusor muscle instability is managed by muscarinic receptor antagonists but their adverse effects limit their uses (14). Some people use traditional herbal medicine as an alternative remedy. Many plants contain flavonoids, alkaloids or glycosides with marked physiological activities. Some of these have been found to

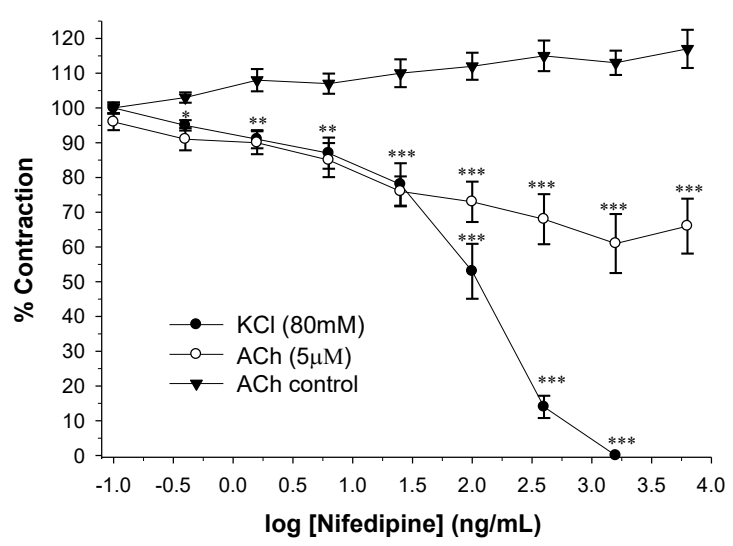

Figure 4. Effect of nifedipine on tension development in rabbit isolated bladder to $\mathrm{KCl}$ and acetylcholine (ACh). Results are given as mean, and vertical bars indicate standard error of mean $(n=5)$. Asterisk symbols indicates statistically significant difference between the test group and its control group ( ${ }^{\star} P<0.05,{ }^{* *} P<0.01,{ }^{* *} P<0.001$, Student's $t$ test).

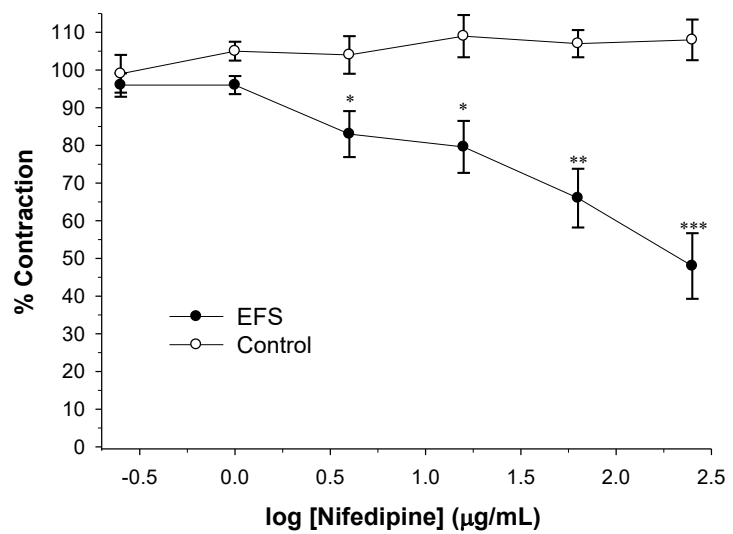

Figure 5. Inhibitory concentration-response curve of non-cumulative addition of nifedipine on tension development in rabbit isolated bladder to electrical field stimulation (EFS, frequency $50 \mathrm{~Hz}$, train duration $1 \mathrm{~s}$, voltage output $6 \mathrm{~V}$ ). Control group represents parallel time-matched tissues treated with equivalent volume of the vehicle. Results are given as mean, and vertical bars indicate standard error of mean $(n=6)$. There was no statistically significant change in response of time-matched controls over the course of the experiment (ANOVA). Asterisk symbols indicates statistically significant difference between the test group and its corresponding vehicle treated control groups $\left({ }^{*} P<0.05\right.$, ${ }^{* *} P<0.01$, ${ }^{* * *} P<0.001$, Student's $t$ test). 
be pharmacologically useful and are regarded as reliable drug source. Quercetin is a natural flavonoid normally found in glycosides forms in the plants and usually a trace of quercetin is existed in aglycone form (7). It has been reported that quercetin has relaxant activities on uterus, ileum and tracheal smooth muscles (7-10). Bioassay studies have confirmed that spasmolytic activity is mainly due to the aglycone form of quercetin (7). Therefore, we have investigated relaxant effect of quercetin on rabbit isolated bladder strips.

Longitudinal strips of bladder strip suspended in the organ bath, manifested miniature spontaneous activities. This is because the urinary bladder smooth muscles are electrically excitable tissues and that's why tissue responded promptly to neuronal stimulation (EFS), cell membrane depolarization $(\mathrm{KCl})$ and receptor stimulation (acetylcholine). Contraction of smooth muscle is caused by an increase in the free $\mathrm{Ca}^{2+}$ ion concentration in the cytosol $(15,16) . \mathrm{Ca}^{2+}$ ions activate the contractile machinery by combining with calmodulin to form a Ca-calmodulin complex which interacts with the enzyme myosin light chain kinase (MLCK). The product of this interaction is a Ca-calmodulin-MLCK complex, which catalysis the phosphorylation of myosin (17). This allows myosin to form cross-bridges with the actin which are rapidly formed and broken down in such a way that two filaments move and cause contraction $(18,19)$. Free $\mathrm{Ca}^{2+}$ ions may come from the extracellular fluid (as in the case of $\mathrm{KCl}$ ) or from inside the cell (as in the case of acetylcholine) $(20,21)$. Addition of $\mathrm{KCl}$ into the organ bath fluid could elicit cell membrane depolarization in the bladder smooth muscle (20). Cell membrane depolarization activates voltagedependent calcium channels and influx of $\mathrm{Ca}^{2+}$ into the cytosol (20). Inhibition of $\mathrm{KCl}$ response by nifedipine confirms activation of L-type calcium channels (22). However, nifedipine only partially reduced acetylcholine and EFS responses indicating that in these cases $\mathrm{Ca}^{2+}$ come from other sources. In fact, there is another mechanism for raising intracellular $\mathrm{Ca}^{2+}$ ions. Some spasmogens interact with their receptors in the plasma membrane and some functions of that spasmogen-receptor interactions are responsible for triggering the release of $\mathrm{Ca}^{2+}$ from intracellular site which trigger contractions without any depolarization (23). EFS appliance triggers release of acetylcholine and other mediators (NANC) from neurons embedded within the muscular layers (24). Acetylcholine induces bladder smooth muscle contraction by acting on muscarinic receptors (25). Responsiveness of the tissue to acetylcholine indicated that the tissues used in this study were mainly comprised of detrusor smooth muscles (26). Acetylcholine mainly activates $M_{2}$ type muscarinic receptors which are coupled to phospholipase- $C$ enzyme system on the cell membrane. Phospholipase activity will increase inositol triphosphate $\left(\mathrm{IP}_{3}\right)$ production and consequently release the $\mathrm{Ca}^{2+}$ ions from intracellular stores
$(26,27)$. Inhibition of acetylcholine response by quercetin could have simply regarded as muscarinic receptor antagonism. However, this is unlikely because in a similar study on rabbit bladder, propantheline only partially reduced EFS responses (28) indicating that inhibition of acetylcholine, $\mathrm{KCl}$ and $\mathrm{EFS}$ responses by quercetin should have more general mechanisms of actions. Quercetin could have caused smooth muscle relaxation either by reducing intracellular free $\mathrm{Ca}^{2+}$ ions concentration or, by interacting with the linkage between $\mathrm{Ca}^{2+}$ and the contractile machinery (e.g. phosphorylation of MLCK). For example some drugs activate second messenger system involving generation of intracellular cyclic adenosine monophosphate (cAMP) and cyclic guanosine monophosphate (cGMP), which cause relaxation of smooth muscle by interacting with contractile machinery (29). Nitric oxide (NO) is also recognized as a mediator involved in bladder function (30). NO is an activator of guanylate cyclase, leading to the formation of cGMP (30). Enhancement of cellular cAMP and cGMP levels is associated with relaxation of bladder smooth muscle. Another mechanism for bladder relaxation is inhibition of enzyme phosphodiesterase which is responsible for degradation of cGMP and cAMP (31).

Both nifedipine and quercetin in concentrationdependent manners inhibited $\mathrm{KCl}$ responses. This may indicate that similar to nifedipine, quercetin also reduces $\mathrm{Ca}^{2+}$ ions influx. This hypothesis is consistent with a report of relaxant effect of quercetin on rat aorta smooth muscle $(32,33)$. Similar suggestion has been made for relaxant effect of quercetin on gastric smooth muscle (34). However, unlike quercetin, nifedipine only partially inhibited contractions evoked by acetylcholine and EFS. This difference means that other mechanism of smooth muscle relaxation could be involved in the case of quercetin. Furthermore, quercetin was four times more potent on the acetylcholine and EFS responses than on the $\mathrm{KCl}$ response. Total inhibition of EFS and acetylcholine allows suggestion that quercetin probably affects intracellular calcium mobilization. Similar suggestion has been made for relaxant effect of another flavonoid "galangin" on pig urinary bladder $(35,36)$. In another study, it has been suggested that relaxant effect of quercetin on vascular smooth muscle is due to inhibition of phosphodiesterase enzyme and therefore enhancement of cAMP level $(37,38)$. This study shows that quercetin is effective in reducing bladder contractions induced by neuronal stimulation, cell depolarization or receptor activation. Therefore, it has potential to cause urinary retention. This is an indication that quercetin, which may worsen urinary retention in patients with hypertrophic prostate. On the other hand, quercetin might be helpful for patients with urinary incontinence. However, effectiveness of quercetin must be evaluated in controlled clinical trials. 


\section{Conclusion}

This study demonstrated that both pretreatment and post-treatment of tissues with quercetin will reduce rabbit bladder contractile to external stimulus. Therefore, quercetin has inhibitory effect on bladder smooth muscle and this means that it could be a suitable lead compound to be investigated for treatment of urinary incontinence.

\section{Acknowledgement}

This project was part of Pharm D. thesis of Sabihe Tabesh as Pharm D. student at Isfahan University of Medical Sciences.

\section{Authors' contributions}

HS was project manager and was responsible for writing the paper. HS supervised the pharmacological studies. ST was responsible for the experimental work and analysis of data. All authors approved the final manuscript for publication.

\section{Conflict of interests}

The authors declare no conflict of interests.

\section{Ethical considerations}

Animal care and experiments were performed in accordance with the guidelines for the care and use of laboratory animal of the Isfahan University of Medical Sciences. The project was confirmed by the ethical committee of the university (IR.MUI.RESEARCH. REC.1398.542).

\section{Funding/Support}

This project was financially supported by Research Department of Isfahan University of Medical Sciences (Project No. 398581).

\section{References}

1. Andersson KE, Arner A. Urinary bladder contraction and relaxation: physiology and pathophysiology. Physiol Rev. 2004;84(3):935-86. doi: 10.1152/physrev.00038.2003.

2. Rang HP, Dale MM, Ritter JM, Flower RJ. Rang \& Dale Pharmacology. 6th ed. London: Churchile Livingstone; 2003. p. 368-84.

3. Sándor Z, Mottaghipisheh J, Veres K, Hohmann J, Bencsik T, Horváth $\mathrm{A}$, et al. Evidence supports tradition: the in vitro effects of Roman chamomile on smooth muscles. Front Pharmacol. 2018;9:323. doi: 10.3389/fphar.2018.00323.

4. Sadraei H, Sajjadi SE, Asghari G, Khalili M. Effect of Matricaria chamomilla hydro-alcoholic and flavonoids rich extracts on rat isolated uterus. J Herbmed Pharmacol. 2020;9(1):35-41. doi: 10.15171/jhp.2020.05.

5. Barnes J, Anderson LA, Phillipson JD. Herbal Medicine. 3rd ed. London: Pharmaceutical Press; 2007. p. 152-5.

6. Li Y, Yao J, Han C, Yang J, Chaudhry MT, Wang S, et al. Quercetin, inflammation and immunity. Nutrients. 2016;8(3):167. doi: 10.3390/nu8030167.

7. Lozoya X, Meckes M, Abou-Zaid M, Tortoriello J, Nozzolillo C,
Arnason JT. Quercetin glycosides in Psidium guajava L. leaves and determination of a spasmolytic principle. Arch Med Res. 1994;25(1):11-5.

8. Morales MA, Tortoriello J, Meckes M, Paz D, Lozoya X. Calciumantagonist effect of quercetin and its relation with the spasmolytic properties of Psidium guajava L. Arch Med Res. 1994;25(1):17-21.

9. Wu CH, Shieh TM, Wang KL, Huang TC, Hsia SM. Quercetin, a main flavonoid in onion, inhibits the PGF2 $\alpha$-induced uterine contraction in vitro and in vivo. J Funct Foods. 2015;19 Pt A:495504. doi: 10.1016/j.jff.2015.09.028.

10. Capasso R, Aviello G, Romano B, Atorino G, Pagano E, Borrelli F. Inhibitory effect of quercetin on rat trachea contractility in vitro. J Pharm Pharmacol. 2009;61(1):115-9. doi: 10.1211/jpp/61.01.0016.

11. de Groat WC, Yoshimura N. Pharmacology of the lower urinary tract. Annu Rev Pharmacol Toxicol. 2001;41:691-721. doi: 10.1146/ annurev.pharmtox.41.1.691.

12. Golbidi S, Laher I. Bladder dysfunction in diabetes mellitus. Front Pharmacol. 2010;1:136. doi: 10.3389/fphar.2010.00136.

13. Deplanne V, Palea S, Angel I. The adrenergic, cholinergic and NANC nerve-mediated contractions of the female rabbit bladder neck and proximal, medial and distal urethra. Br J Pharmacol. 1998;123(8):1517-24. doi: 10.1038/sj.bjp.0701757.

14. Chapple CR, Yamanishi T, Chess-Williams R. Muscarinic receptor subtypes and management of the overactive bladder. Urology. 2002;60(5 Suppl 1):82-8. doi: 10.1016/s0090-4295(02)01803-4.

15. Hill-Eubanks DC, Werner ME, Heppner TJ, Nelson MT. Calcium signaling in smooth muscle. Cold Spring Harb Perspect Biol. 2011;3(9):a004549. doi: 10.1101/cshperspect.a004549.

16. Chess-Williams R. Muscarinic receptors of the urinary bladder: detrusor, urothelial and prejunctional. Auton Autacoid Pharmacol. 2002;22(3):133-45. doi: 10.1046/j.1474-8673.2002.00258.x.

17. Bolton TB, Prestwich SA, Zholos AV, Gordienko DV. Excitationcontraction coupling in gastrointestinal and other smooth muscles. Annu Rev Physiol. 1999;61:85-115. doi: 10.1146/annurev. physiol.61.1.85.

18. Arner A, Pfitzer G. Regulation of cross-bridge cycling by $\mathrm{Ca} 2+$ in smooth muscle. Rev Physiol Biochem Pharmacol. 1999;134:63146. doi: 10.1007/3-540-64753-8_3.

19. Walsh MP. Calmodulin and the regulation of smooth muscle contraction. Mol Cell Biochem. 1994;135(1):21-41. doi: 10.1007/ bf00925958.

20. Ratz PH, Berg KM, Urban NH, Miner AS. Regulation of smooth muscle calcium sensitivity: $\mathrm{KCl}$ as a calcium-sensitizing stimulus. Am J Physiol Cell Physiol. 2005;288(4):C769-83. doi: 10.1152/ ajpcell.00529.2004.

21. Elorriaga M, Anselmi E, Hernandez JM, D'Ocon P, Ivorra D. The sources of $\mathrm{Ca} 2+$ for muscarinic receptor-induced contraction in the rat ileum. J Pharm Pharmacol. 1996;48(8):817-9. doi: 10.1111/ j.2042-7158.1996.tb03980.x.

22. Katz AM. Pharmacology and mechanisms of action of calciumchannel blockers. J Clin Hypertens. 1986;2(3 Suppl):28S-37S.

23. Herrera GM, Heppner TJ, Nelson MT. Regulation of urinary bladder smooth muscle contractions by ryanodine receptors and BK and SK channels. Am J Physiol Regul Integr Comp Physiol. 2000;279(1):R60-8. doi: 10.1152/ajpregu.2000.279.1.R60.

24. Creed KE, Ishikawa S, Ito Y. Electrical and mechanical activity recorded from rabbit urinary bladder in response to nerve stimulation. J Physiol. 1983;338:149-64. doi: 10.1113/jphysiol.1983. sp014666.

25. Sellers DJ, Chess-Williams R. Muscarinic agonists and 
antagonists: effects on the urinary bladder. Handb Exp Pharmacol. 2012(208):375-400. doi: 10.1007/978-3-642-23274-9_16.

26. Hegde SS, Eglen RM. Muscarinic receptor subtypes modulating smooth muscle contractility in the urinary bladder. Life Sci. 1999;64(6-7):419-28. doi: 10.1016/s0024-3205(98)00581-5.

27. Putney JW, Tomita T. Phospholipase $\mathrm{C}$ signaling and calcium influx. Adv Biol Regul. 2012;52(1):152-64. doi: 10.1016/j. advenzreg.2011.09.005.

28. Sadraei H, Sajjadi SE, Tarafdar A. Antispasmodic effect of hydroalcoholic and flavonoids extracts of Dracocephalum kotschyi on rabbit bladder. J Herbmed Pharmacol. 2020;9(2):145-52. doi: 10.34172/jhp.2020.19.

29. Lincoln TM, Cornwell TL. Towards an understanding of the mechanism of action of cyclic AMP and cyclic GMP in smooth muscle relaxation. Blood Vessels. 1991;28(1-3):129-37. doi: 10.1159/000158852.

30. Mumtaz FH, Khan MA, Thompson CS, Morgan RJ, Mikhailidis DP. Nitric oxide in the lower urinary tract: physiological and pathological implications. BJU Int. 2000;85(5):567-78. doi: 10.1046/j.1464-410x.2000.00459.x.

31. Rahnama’i MS, Ückert S, Hohnen R, van Koeveringe GA. The role of phosphodiesterases in bladder pathophysiology. Nat Rev Urol. 2013;10(7):414-24. doi: 10.1038/nrurol.2013.101.

32. Chen CK, Pace-Asciak CR. Vasorelaxing activity of resveratrol and quercetin in isolated rat aorta. Gen Pharmacol. 1996;27(2):363-6. doi: 10.1016/0306-3623(95)02001-2.

33. Duarte J, Pérez Vizcaíno F, Utrilla P, Jiménez J, Tamargo J, Zarzuelo A. Vasodilatory effects of flavonoids in rat aortic smooth muscle. Structure-activity relationships. Gen Pharmacol. 1993;24(4):85762. doi: 10.1016/0306-3623(93)90159-u.

34. Rotondo A, Serio R, Mulè F. Gastric relaxation induced by apigenin and quercetin: analysis of the mechanism of action. Life Sci. 2009;85(1-2):85-90. doi: 10.1016/j.lfs.2009.04.022.

35. Dambros $\mathrm{M}$, de Jongh $\mathrm{R}$, van Koeveringe GA, Bast A, van Kerrebroeck PE. Galangin protects pig detrusor nerves from repetitive field stimulation and anoxia/glucopenia injury. Urology. 2005;66(6):1327-31. doi: 10.1016/j.urology.2005.06.095.

36. Dambros M, van Deutekom M, de Jongh R, van Koeveringe GA, De Mey JG, van Kerrebroeck P. The inhibitory effect of the flavonoid galangin on urinary bladder smooth muscle contractility is mediated in part by modulation of $\mathrm{Ca} 2+$ release from intracellular stores. Planta Med. 2005;71(10):962-4. doi: 10.1055/s-2005-864180.

37. Chiwororo WD, Ojewole JA. Dual effect of quercetin on rat isolated portal vein smooth muscle contractility. Cardiovasc J Afr. 2010;21(3):132-6.

38. Chan EC, Pannangpetch P, Woodman OL. Relaxation to flavones and flavonols in rat isolated thoracic aorta: mechanism of action and structure-activity relationships. J Cardiovasc Pharmacol. 2000;35(2):326-33. doi: 10.1097/00005344-200002000-00023. 